\title{
The Discourse Marker Issona and Island Culture
}

\author{
Yoon-kyoung Joh \\ Mokpo National University, Korea
}

Publication Information:

Received 23 October 2019, Accepted 11 November 2019, Available online 16 December 2019

DOI: 10.21463/jmic.2019.08.2.04

\begin{abstract}
This paper criticizes the predominant relevance theory for discourse markers for the reason that it suggests too broad a notion which is irrefutable. Instead, this paper explains the Korean discourse marker issona under the framework advocated by Leech (1983). Leech (1983) proposes six maxims of politeness and this paper claims that two maxims the Agreement Maxim and the Sympathy Maxim - explain the reason why the discourse marker issona is used so frequently in the Shinan county in Korea. It is employed as an endeavor to minimize disagreement and antipathy between the speaker and the addressee that might arise when making a strong commitment while expecting disagreement. This account is especially interesting since it can be well understood under the special isolated environment in small islands. That is, the isolated culture of small islands can explain the enhanced desire to minimize tension and to maximize solidarity among the interlocutors. The Korean expression issona also highlights the metalinguistic function of discourse markers that Erman (2001) newly proposes.
\end{abstract}

\section{Keywords}

discourse marker, relevance theory, politeness maxim, metalinguistic function, solidarity

\section{Introduction}

According to Jucker (1993), Hölker (1991) describes four basic conditions of discourse markers as in (1) and I would like to claim that the expression issona ${ }^{1}$ used in the Shinan county in Korea is a discourse marker in terms of them. 
(1) a. They do not change the truth conditions of what is uttered.

b. They add nothing to the propositional content.

c. They are connected to the speech situation but not to the situation being talked about.

d. They have an emotive function rather than a referential function.

The occurrence of issona in (2) meets all the conditions of discourse markers described above. First, it does not change the semantic content of the utterance where it occurs. Furthermore, it adds nothing to the truth conditions of the utterance where it is used. It has a close relation with the speech circumstance rather than the propositional content being discussed. Also, it has an extra emotive functions of enforcing solidarity with the addressee by relieving tension that might arise when making a strong commitment about the upcoming utterance.

(2) a. kyosunim, issona!

professor, ISSONA!

b. wuli cip-ey ka-se siksa-ha-seyyo.

our house -Loc go -Con meal-do -Hon .

'Let's go to our house and have a meal.'

This paper will examine the basic functions of the Korean discourse marker issona exclusively used in the Shinan county under the framework proposed by Leech (1983). The Shinan county in Korea is composed of many islands and the unique linguistic elements of this county can be considered as the characteristics of island dialects. Thus, the primary goal of this paper is to examine a discourse marker which reveals distinct island cultures.

This paper is organized as follows. First, section 2 will introduce various definitions and characteristics of discourse markers. Then, section 3 will introduce Jucker (1993) to discuss a well-established discourse marker well in English and the relevance-theoretic account on it. Section 4 will scrutinize the functions of the discourse marker issona and propose a new account for it. In presenting an account, I will criticize the plausible relevance-theoretic explanation and, instead, resort to the maxims of politeness. I will also point out that the examination of the discourse marker issona tells us that we need to identify the metalinguistic function of discourse markers along with the textual and interpersonal functions. Finally, section 5 will conclude this paper.

\section{Characteristics of Discourse Markers}

Blackemore (1987) defines discourse markers as in (3a) while Brinton (1996), citing Redeker (1990) and Redeker (1991), defines them as in (3b). Goldberg (1980) has also provided the definition of discourse markers as in (3c). All of them commonly claim that discourse markers serve to signal relations of discourse units, rather than developing the discourse itself. 
(3) a. Discourse markers are expressions used to signal how the relevance of one discourse part relies on another.

b. Discourse markers are expressions that are employed to indicate the connection of an utterance to the immediate context with the main function of bringing to the addressee's attention a linkage of the upcoming utterances with the given discourse segment.

c. Signaling devices that show the speaker's construal of the contribution's relation to the information pact as established by the immediately preceding context.

To discuss more details of discourse markers, I would like to introduce Brinton (1996) who summarizes the general characteristics of pragmatic markers as in (4). ${ }^{2}$

(4) a. Pragmatic markers are most of the time a characteristic of oral discourse rather than of a written discourse.

b. Pragmatic markers show up frequently in oral discourse, from time to time with more than one appearance in one sentence.

c. Pragmatic markers are stylistically stigmatized and very often negatively evaluated, especially in written discourse.

d. Pragmatic markers are often short items which are phonologically reduced or unstressed.

e. Pragmatic markers constitute a separate tone group especially equipped with falling-rising or rising intonation.

f. Pragmatic markers have little propositional meaning, which is difficult to specify lexically.

g. Pragmatic markers appear either outside of the relevant syntactic structure or loosely being attached to it and thus have no clear syntactic function.

h. Pragmatic markers are regarded to be optional rather than obligatory.

i. Pragmatic markers are considered to be marginal forms, in the sense that they are the forms which are left over by the core grammar.

j. Pragmatic markers can be multi-functional, operating on the local and global levels simultaneously, as well as on different planes.

As described above, we can understand pragmatic markers as the forms which are oral, often stylistically stigmatized, phonologically reduced and operate at the pragmatic level. Furthermore, they are optional, marginal and multi-functional. In the next section, I will introduce an example of a discourse marker which has been scrutinized in depth. In doing so, I will also introduce the most common framework that has dealt with discourse markers in general.

\section{Discourse Marker Well and Relevance Theory}

Jucker (1993) claims that the discourse marker well is a marker that signals to the addressee that the context processed by the preceding utterance is not the most "relevant" context for the upcoming utterance. In claiming so, Jucker (1993) 
identifies four functions of the discourse marker well. In the following, I will briefly introduce Jucker (1993) who cites diverse related studies about the four functions.

First, the discourse marker well is a marker of insufficiency. Originally, Lakoff (1973) has examined the discourse marker well in conversational situations and observed that it is employed when the speaker does not provide the direct answer to the questioner's request. Thus, the employment of the discourse marker well implies a sense of insufficiency. The insufficiency can be covered by the addressee or by the speaker in the process of providing additional information in the subsequent discourse.

According to Jucker (1993), Lakoff (1973) also illustrates the insufficiency sense of well with the examples in (5). For the question in (5a), the answers provided in (5b) and (5c) are the same truth conditionally. However, the answer in (5b) and the answer in (5c) are not interchangeable. The answer in (5b) provides all the information about the question in (5a) while the answer in (5c) is neither a complete nor a direct answer to the question in (5a). For the answer in (5c), a followup question such as "What do you mean by well, yes?" would probably be expected.

(5) a. Did you kill your wife?

b. Yes.

c. Well, yes.

Jucker (1993) also mentions that Schiffrin (1987) adds more examples to this claim. For instance, in the example in (6), the discourse marker well is employed when Sally cannot provide sufficient answers to the question that Zelda asked. Sally cannot say either yes or no which would be the most relevant answer to the question asked by Zelda and thus tries to fill in more background assumptions to satisfy the request. It is claimed that this circumstance is the most typical context where the discourse marker well is used.

a. Zelda: Are you from Texas?

b. Sally: Well I was raised uh out in the countryside. And then I lived for about two years in the downtown Philadelphia. And then I came here to go to school.

Second, the discourse marker well can be used to reduce confrontation between the speaker and the addressee. According to Jucker $(1993)$, Owen $(1981,1983)$ originally observes that the discourse marker well is often utilized under face-threatening circumstances where an assessment is disagreed as in (7), a request is refused as in (8) or an offer is rejected as in (9).

(7) a. They must concern about you though Katie, don't they, your mother and father, when you're experimenting with all the jumps.

b. Er well they made sure to come to all the shows.

(8) a. Can I just look at them?

b. Um well I'm not permitted to do that. 
(9) a. What about going there on your way or doesn't that allow you sufficient time.

b. Well no I'm working here.

Jucker (1993) also cites Watts (1986) who claims that the discourse marker well is a face-threat minimizer. In the discourse presented in (10), there is no apparent face-threatening act. Yet, a face-threatening situation can arise when the respondent cannot supply the most relevant answer to the preceding context. In other words, according to Watts (1986), the possibility of face-threatening arises when the interlocutors cannot immediately follow the maxim of relevance.

(10) a. It must be rather disturbing when your cat goes around spraying all the time, though, mustn't it?

b. It's not so bad if it's a female that's spraying, but if you have a good tomcat that's spraying, well, it can empty the room, it can empty the house.

Third, Jucker (1993) also claims that the discourse marker well is used as a frame which functions to separate discourse units. Thus, it is observed that the discourse marker well is not often positioned the beginning of a discourse unit. The discourse marker well is employed to reorient the discourse participants to new background assumptions which were not quite relevant in the preceding discourse. In (11a), the discourse marker well is used to change the topic of the interview, while in (11b), it is employed to shift the discourse to the reported speech.

(11) a. but if they wanted students nearby to talk to, then I would be very pleased to stay, and got a letter mentioning they have arranged for you to stay - well let's have the interview to begin with.

b. and I said well I don't believe I can write - and this sort of fifty-two page booklet about that big.

Fourth, Jucker (1993), giving credit to Svartvik (1980), also observes that the discourse marker well can be used as a delaying strategy. For instance, in the discourse presented in (12), the discourse marker well is used to earn time for thinking about the appropriate answer.
a. on the floor
b. on on well on you know on hatchway there.

As mentioned above, Jucker (1993) claims that all the four functions of the discourse marker well can be understood under the rubric of the notions of context in the relevance theory and Jucker (1993) summarizes the notions of context in the relevance theory as in (13).

(13) a. Every utterance has a guarantee of its optimal relevance.

b. The relevant context is marked as part of the utterance understanding.

c. Discourse coherence is the result of negotiating relevant background information. 
To be more specific, the statement in (13a) points out that, when an utterance is made, it should basically be worthwhile to process. If an utterance cannot bring about enough effects for the worth of processing efforts, the utterance is not considered as an optimal one. The most relevant utterance is the one that achieves a maximal effect for a minimal effort. In other words, the more effects an utterance induces, the more relevant the utterance is. Looking at the opposite side, the smaller the processing efforts are, the higher the relevance of the utterance becomes. In other words, the relevance theory claims that context is not given statically but is created by the dynamic interpretation of the utterances. Utterances are interpreted under the relevant context which is composed of the linguistic discourse context and the mutually known background context.

Yet, the relevance theory argues that the speakers and the addressees do not have any mutual assumptions in a strict sense but they share a so-called mutual cognitive environment. The mutual cognitive environment is not static, either. It fluctuates by the processes of negotiating and renegotiating throughout the conversation. The same discourse context can be conceived as relevant or coherent by one discourse participant and as irrelevant or incoherent by another discourse participant. The judgment relies on their assessment whether the utterances in a given context can be considered as optimally relevant ones for the following utterance. Under these notions of context, Jucker (1993) concludes that the seemingly diverse functions of the discourse marker well can be summarized as a signifier that points out that the context of the utterances that precede the discourse marker well is not the most "relevant" context for the subsequent context.

The discussion of this section seems interesting and the reason why I introduce these studies on English discourse marker well is because many parts of it overlap with the functions of the discourse marker issona that we will concern in the following section. Yet, in the proposal of this paper, I will resort to a new framework to account for the similar discourse marker used in the Shinan county in Korea since the new framework of this paper is believed to be better suited to explain the fundamental motivations to employ the discourse marker issona itself rather than superficially cover the functions.

\section{Proposal}

This section will scrutinize the functions of the Korean discourse marker issona and a possible account for them. Yet, different from previous works on discourse markers that rely on the relevance theory, this section will introduce the maxims of politeness that Leech (1983) puts forth and explain the discourse marker issona under the framework. Lastly, I will point out that the examination of the discourse marker issona tells us that the metalinguistic function of discourse markers should not be ignored along with textual and interpersonal functions.

\subsection{The Functions of the Discourse Marker Issona}

The expression issona can be used as a predicate which shares much of the propositional content with the predicate issta 'be.' Yet, the peculiar form of issona used in the Shinan county in Korea adds an extra meaning to the utterance where it is used as a main predicate. It emphasizes that not only the speaker but also the addressee know the information conveyed. For instance, the utterance in (14a) simply states that there is a key in the schoecase of the 
speaker's house. However, the utterance in (14b) reminds the addressee of the mutually known fact that there is a key in the shoecase of the speaker's house. Furthermore, it is reported that the expression issona is used when the evidence to support the mutually known fact is obvious. As a main predicate, the form issona dynamically involves the addressee's state of knowledge more than the plain expression issta.

a. yelsoyka wuli cip sinpalcangey iss-ta.

key -Nom our house shoecase -Loc is -Dec

'The key is in the shoecase of our house.'

b. yelsoy-ka wuli cip sinpalcang-ey issona

key -Nom our house shoecase -Loc ISSONA

'(Both of us know that) the key is in the shoecase of our house.'

When it is used with a vocative, the form issona functions as a discourse marker and does not affect the truth conditional meaning of the utterance where it is employed. The most typical example of issona is shown in (15). It is usually used with the vocative that addresses the superior of the speaker and is followed by a proposal that the addressee might disagree but the speaker would like to insist or pursue. In (15), the speaker desires to have a meal in the speaker's house with the addressee. With this proposal in mind, however, the speaker expects a rejection due to possible misunderstandings that can be caused by the meal. Under this circumstance, the occurrence of issona is reported to be the most appropriate.
a. kyosunim, issona! professor, ISSONA!
b. wuli cip-ey ka-se siksa-ha-seyyo.
Our house -Loc go -Con meal-do -Hon .
'Let's go to our house and have a meal.'

Let me introduce another typical example of the discourse marker issona. In the example in (16), issona is employed before the speaker mentions a new proposal he or she would like to make. The expression issona is felicitous especially when the speaker predicts a possible disagreement but would like to express his or her firm commitment to the proposal.
a. kyosunim, issona!
professor, ISSONA!
b. cey-ka saylopkey ceyan-hako siphun cem-i iss-seyyo.
I-Nom newly propose-do would like to point -Nom is -Hon
'There is a point that I would like to newly propose.'

In (17), it is reported that the use of issona sounds unnatural when it is followed by an utterance which thanks the acceptance of the addressee. Yet, it is further noted that, if the presence of the discourse marker issona is enforced, the 
possible implication is that the acceptance was not the natural kind but a result of the speaker's much endeavor to persuade the addressee who would initially like to disagree with the speaker's opinion.
a. \#kyosunim, issona! professor, ISSONA!
b. cey uykyen-ey tonguy-hay cwu-sye-se kamsahapni-ta. My opinion -Dat agree-do give -Hon -because appreciate -Dec . 'I appreciate because you agree with my opinion.'

The discourse marker issona is also employed when the speaker would like to earn time to talk about his or her committed ideas that might be disagreed. Thus, just like the English discourse marker well, it can be used as a delaying strategy. The example in (18) shows us that the expression issona is appropriate when the speaker hesitates to talk about his or her thoughts or ideas.
a. kyosunim, issona!
professor, ISSONA!
b. ettehkey malssumtulyeya halci komin-sulep-supnita. how tell do concern-kind of -Dec .
'I'm kind of concerned about how to tell you (about this).'

As the examples above show us, most of the time, the discourse marker issona is employed in a discourse-initial position when introducing a new topic which seems difficult. Yet, when it is used in the middle of a discourse, the employment of the expression issona marks the change of the topic, as shown in (19).

(19) a. onul semyehayng-ul kyeyhoyk-hayess-supnita.

Today island trip -Acc plan-do -Dec .

'Today we planned an island trip.'

b. kyosunim, issona! professor, ISSONA!

c. yeysan mwuncey-ka iss-supnita. budget problem -Nom is -Dec. 'There is a budget problem.'

As further illustrated in (20), it is reported that the use of issona in the middle of a conversation with no evident topic shifting sounds less natural. However, it is also noted that, if the presence of issona is enforced, it might produce the impression that the utterance that follows issona was not the most expected situation in the context and thus there is an implicit shifting of the situational context. 
(20)

a. onul semyehayng-ul kyeyhoyk-hayess-supnita.

Today island trip -Acc plan-do -Dec .

'Today we planned an island trip.'

b. \#kyosunim, issona!

professor, ISSONA!

c. culkewun yehayng-i toyessu-myen cohkeysssupnita.

pleasant trip -Nom become-if would like -Dec .

'I would like it if it becomes a pleasant trip.'

To sum, the discourse marker issona is used when the speaker would like to introduce an utterance which might cause disagreement of the addressee but which the speaker would like to newly make a strong commitment to. Since it is employed to introduce or shift to a rather difficult topic, it can also be recognized as a delaying strategy.

\subsection{Maxims of Politeness}

In the literature, it seems that the most predominant approach to discourse markers is the relevance theory. Yet, even though many discourse markers including English well have been accounted for by the relevance theory as discussed in section 3, the most critical problem lies in the fact that the framework presents a non-refutable argument. The notion of relevance is so vague that it can apply to anything. In other words, there is nothing that cannot be explained by the relevance theory if we try to view the notion of relevance in a broad sense. Does this mean that it can explain everything? I doubt it. On the other hand, it is hard to specifically address the expectation about the possible disagreement of the addressee and the speaker's firm commitment under the notions of the context explicated by the relevance theory, let alone explaining the very motivations why the discourse marker issona is used widely in the Shinan county.

Thus, this paper would like to turn to an alternative framework: the maxims of politeness that Leech (1983) suggests instead of the relevance theory. Leech's (1983) maxims of politeness comprise the following 6 maxims in (21). 
(21) a. Tact Maxim (in impositives and commissives)

(i) Minimize cost to other

(ii) Maximize benefit to other

b. Generosity Maxim (in impositives and commissives)

(i) Minimize benefit to self

(ii) Maximize cost to self

c. Approbation Maxim (in expressives and assertives)

(i) Minimize dispraise of other

(ii) Maximize praise of other

d. Modesty Maxim (in expressives and assertives)

(i) Minimize praise of self

(ii) Maximize dispraise of self

e. Agreement Maxim (in assertives)

(i) Minimize disagreement between self and other

(ii) Maximize agreement between self and other

f. Sympathy Maxim (in assertives)

(i) Minimize antipathy between self and other

(ii) Maximize sympathy between self and other

Let me briefly explain each maxim with Leech's examples. First, to be polite, we can increase the indirectness of an utterance while keeping the same propositional content as in (22). The indirect illocutions enhance the degree of optionality and reduces the tentative force associated. When the tentative force is diminished, the cost imposed on others is also reduced and thus become more polite. This is the bottom line of the Tact Maxim.

(22) a. Answer the phone.

b. I want you to answer the phone.

c. Will you answer the phone?

d. Can you answer the phone?

e. Would you mind answering the phone?

f. Could you possibly answer the phone?

At a first glance, it seems that there is no big motivation to make a distinction between the Tact Maxim and the Generosity Maxim since they govern the same situation. The only difference between them is that the situation handled is reversed. Yet, Leech (1983) claims that the illocutionary forces of the following utterances are governed by the Generosity Maxim, but not by the Tact Maxim, since they specifically refer to the self, not others. Thus, it is claimed that the asymmetry between the two related maxims must be kept distinct.

(23) a. Could I borrow this electric drill?

b. I wouldn't mind a cup of coffee. 
The Approbation Maxim dictates that we should avoid using unpleasant words about others and hearers. In terms of this maxim, the utterance in (24a) is highly valued whereas the utterance in (24b) is not.

(24) a. What a marvelous meal you cooked!

b. What an awful meal you cooked.

The utterances in (25) are understatements. The reason can be found in the Approbation Maxim. When the Approbation Maxim is operating, the inability to express a favorable opinion implies dispraise.

(25) a. You could be more careful.

b. Her performance was not so good as it might have been.

C. A: Do you like these apricots?

B: I've tasted better.

In terms of the Modesty Maxim, we can agree with the compliment about others but not about ourselves, as shown in (26) and (27). Also, the contrasts described in (28) and (29) show us that self-dispraise is quite common but dispraise about others bring about awkward utterances. Furthermore, as illustrated in (30), the understatement about one's generosity is acceptable while the exaggeration about one's generosity sounds quite abnormal. These contrasts can be explained by the Maxim of Modesty.

(26) a. They were so kind to us.

b. Yes, they were, weren't they?

(27) a. You were so kind to us.

b. \#Yes, I was, wasn't I?

(28) a. How stupid of me!

b. \#How clever of me!

(29) a. \#How stupid of you!

b. How clever of you!

(30) a. Please accept this small gift as a token of our esteem.

b. \#Please accept this large gift as a token of our esteem.

The Maxim of Agreement tells us that it is preferable to provide a partial disagreement as in (32) and (33) rather than a complete disagreement as in (31). The reply in (31) is perceived to be very rude and not very desirable and Leech (1983) claims that the Maxim of Agreement explains the oddity of the utterance in (31b). 
(31) a. It was an interesting exhibition, wasn't it?

b. \#No, it was very uninteresting.

(32) a. English is a difficult language to learn.

b. True, but the grammar is quite easy.

(33) a. The books are tremendously well written.

b. Yes, well written as a whole, but there are some rather boring patches, don't you think?

Finally, the Maxim of Sympathy explains why the utterance in (34a) is preferable to the utterance in (34b). Yet, the Sympathy Maxim is not confined to expressions of condolence for misfortunes, but can be extended to general situations where the speaker desires to be in the same vein with the addressee(s) or others.

(34) a. I'm terribly sorry to hear that your cat died.

b. \#I'm terribly pleased to hear that your cat died.

Among the six maxims described above, the maxims relevant to the discourse marker issona are the Agreement Maxim and the Sympathy Maxim. The maxims guide the speaker to 'minimize disagreement between self and other' and 'minimize antipathy between self and other.' The employment of the discourse marker issona is an endeavor to abide by the two maxims of politeness when expecting disagreement between self and other but wanting to pursue the speaker's will. Under the circumstance, the speaker tries to relieve the tension between the speaker and the addressee by making an explicit signal to be polite.

An aspect that should also be noted about the account presented above is the fact that the two maxims of politeness seem to be highly respected especially in small islands. The reason might be attributed to the distinct culture of islands which can be characterized by isolation. In isolated circumstances, discourse participants seem to have more desire to enhance the solidarity sense among them. This is probably why the people in the Shinan county in Korea use the discourse marker issona very much, putting great efforts to abide by maxims of politeness.

\subsection{The Metalinguistic Function}

Finally, this section will emphasize that the study of issona proves the existence of the metalinguistic function of discourse markers, too. Brown and Yule (1983), Brionton (1996), Halliday (1970b), Jakobson (1960), Redeker (1990), and many others identify only two functions of discourse markers. They argue that discourse markers are working at the textual level and the interpersonal level. At the textual level, discourse markers serve to shift a fragmented discourse into a coherent discourse. At the interpersonal level, discourse markers function to ensure that the conversational channel is kept smooth between discourse participants.

Erman (2001), however, prefers to characterize the two levels as two domains and identify their functions as textual monitors and social monitors. In addition, Erman (2001) adds one more category to the two functions of discourse 
markers. The third category is characterized as metalinguistic monitors. That is, discourse markers as metalinguistic monitors can express the speaker's commitment to the utterances he or she makes and to their values. In a sense, metalinguistic monitors play the role of modals since they inform the addressee about the speaker's level of commitment to their utterances.

The metalinguistic function works when the speaker highlights the illocutionary force of the sentences he or she makes. To be more specific, as the examples below illustrate, the metalinguistic function of the discourse marker you know serves as hedges and approximators that adjust the level of commitment of the speaker. In the examples from (35) to (38), the discourse marker you know is claimed to bring about a toning down effect.

She said you're, you're nice, you're pretty, you know whatever.

a. We spent about an hour and a half, just arranging for us to take one occasional student, you know the sort of thing.

b. Oh yes, frightful.

Henry: I'm not a - we're all not perfect, y'know l'm not perfect Zelda, after all.

(38) a. Stop the tape. Don't even tape this.

b. I don't know if I'll be allowed, I'll have to ask cos, you know how it is.

The current study sheds light on Erman (2001) since the major function of the discourse marker issona operates in the metalinguistic domain as well. It is employed to politely convey the speaker's strong commitment to the upcoming utterance or to the upcoming topic, while expecting possible disagreement of the addressee. This fact leads us to the conclusion that, different from the popular view on discourse markers which were identified only with two functions, we need the third category of metalinguistic domain for discourse markers, as Erman (2001) claims.

\section{Conclusion}

There are four major functions of the discourse marker issona. First, it signals that the speaker predicts possible disagreement of the addressee. Second, it expresses that the speaker wants to make a strong commitment to the upcoming utterance. Third, the discourse marker issona is used when the speaker has a strong desire to introduce or shift to a new topic which might be a little bit difficult and thus burdensome to the addressee. Fourth, since it is usually used to induce a difficult issue, it often functions as a delaying marker. To explain the functions of issona, this paper has turned to the maxims of politeness that Leech (1983) puts forth. Especially, this paper claims that the Agreement Maxim and the Sympathy Maxim explain the employment of the discourse marker issona since it is fundamentally motivated to ease the tension between self and other when disagreement and antipathy are expected. That is, it is employed to politely make a strong commitment when predicting possible disagreement by introducing or shifting to difficult topics 
which can be burdensome to the addressee. The study of the Korean discourse marker issona also supports the claim of Erman (2001) who proposes that we need to recognize discourse markers' metalinguistic function that signifies the degree of commitment along with the textual and interpersonal functions.

\section{Endnotes}

1. I would like to note that some speakers say issonan rather than issona. Yet, there is no big difference between the two variants. This paper focuses on the form of issona which seems to be used more predominantly.

2. I would like to note that some parts of the characteristics described by Brinton (1996) are omitted in (4) since they, in their original forms, do not seem persuasive enough.

\section{References}

Blakemore, D., 1987. Semantic Constraints on Relevance. Blackwell, Oxford.

Brinton, L. J., 1996. Pragmatic Markers in English: Grammaticalization and Discourse Functions. Mouton de Gruyter, Berlin.

Brown, G., Yule, G., 1983. Discourse Analysis. Cambridge University Press, Cambridge.

Erman, B., 2001. Pragmatic markers revisited with a focus on you know in adult and adolescent talk. Journal of Pragmatics 33: $1337-1359$.

Goldberg, J. A., 1980. Discourse Particles: An Analysis of the Role of Y'know, I Mean, Well and Actually in Conversation. Ph.D. Dissertation, University of Cambridge.

Halliday, M. A. K., 1970. Language structure and language function, in: Lyons, J. (Ed.), New Horizons in Linguistics, Penguin Books, Harmondsworth, pp. 140-165.

Hölker, K., 1991. Französisch: Partikelforschung. Lexikon der Romanistischen Linguistik 1: 77-88.

Jakobson, R., 1960. Closing statement: Linguistics and poetics, in: Sebeok, T. A. (Ed.), Style in Language, MIT Press, Massachusetts, pp. 350377.

Jucker, A. H., 1993. The discourse marker well: A relevance-theoretical account. Journal of Pragmatics 19: 435-452.

Lakoff, R., 1973. Questionable answers and answerable questions, in: Kachru, B.B., Lees, R.B., Malkiel, A., Pietrangeli, A., Sporta, S., (Eds.), Issues in Linguistics, University of Illinois Press, Urbana, pp.453-467.

Leech, G., 1983. Principles of Pragmatics. Longman, London.

Owen, M., 1981. Conversational units and the use of 'well...', in Werth, P. (Ed.), Conversation and Discourse, Croom Helm, London, pp. 99-106. Owen, M., 1983. A Study of Language Use in Social Interaction. Mouton, Berlin.

Redeker, G., 1990. Ideational and pragmatic markers of discourse. Journal of Pragmatics 14: 367-381.

Redeker, G., 1991. Review article: Linguistic markers of discourse structure. Linguistics 29: 1139-1172. 
Shiffrin, D., 1987. Discourse Markers. Cambridge University Press, Cambridge.

Svartvik, J., 1980. 'Well' in conversation, in: Greenbaum, S., Leech, G., . Svartvik, J. (Eds.), Studies in English Linguistics for Randolph Quirk, Longman, London, pp. 167-177.

Watts, R., 1986. Relevance in conversational moves: A reappraisal of 'well." Studia Anglica Posnaniensia 19: 37-59. 